Jelliffe, D. B. (1954). In Malnutrition in African Mothers, Infants and Young Children. Report of the Second Inter-African Conference on Nutrition, p. 230. London: H.M. Stationery Office.

Krzywicki, L. (1934). Primitive Society and its Vital Statistics, p. 127. Warsaw: J. Mianowski Institute.

Macy, I. G., Nims, B., Brown, M. \& Hunscher, H. A. (1930). Amer. F. Dis. Child. 39, I 86.

Malcolm, S. (1952). Report on Research Conducted in the New Hebrides during 1951. South Pacific Commission, Noumea, New Caledonia, Rep. nos. 6-7.

Mead, M. (1947). Transactions of the First Conference on Problems of Early Infancy, p. 36. New York: Josiah Macy Jr. Foundation.

Morrison, S. D. (1952). Tech. Commun. Bur. Anim. Nutr. Aberd. no.18.

Nhonoli, A. M. M. (1954). E. Afr. med. F. 31, I.

Olmsted, R. W. (1947). Transactions of the First Conference on Problems of Early Infancy, p. 49. New York: Josiah Macy Jr. Foundation.

Platt, B. S. (1936). Chin. med. F. 5o, 410.

Platt, B. S. (r953). Int. Congr. trop. Med. v. Istanbul, I, 155.

Platt, B. S. (1954). In Malnutrition in African Mothers, Infants and Young Children. Report of the Second Inter-African Conference on Nutrition, p. 29I. London: H.M. Stationery Office.

Platt, B. S. \& Gin, S. X. (1938). Arch. Dis. Childh. 13, 343.

Platt, B. S. \& Moncrieff, A. (1947). Brit. med. Bull. 5, I77.

Ploss, H. H., Bartels, M. \& Bartels, P. (1935). Woman, Vol. 3, p. 218 . London: Heineman.

Ritchie, J. F. (1943). The African as Suckling and as Adult. Paper no. 9 of the Rhodes-Livingstone Institute.

Second Inter-African Conference on Nutrition. (1954). Malnutrition in African Mothers, Infants and Young Children, p. 343. London: H.M. Stationery Office.

Sigerist, H. E. (195 I). History of Medicine, Vol. I. Primitive and Archaic Medicine, p. I 17. Oxford: University Press.

Stewart, H. L. Jr. \& Pratt, J. P. (1939). Endocrinology, 25, 347.

Still, G. F. (193 I $a$ ). The History of Paediatrics, p. 455. Oxford: University Press.

Still, G. F. (1931 $b$ ). The History of Paediatrics, p. I19. Oxford: University Press.

Still, G. F. (193 I $c)$. The History of Paediatrics, p. 390. Oxford: University Press.

Still, G. F. ( $193 \mathrm{I} d)$. The History of Paediatrics, p. 50. Oxford: University Press.

Still, G. F. (1931e). The History of Paediatrics, p. 1zo. Oxford: University Press.

Talbot, D. A. (r915). Woman's Mysteries of a Primitive People, p. 26. London: Cassell \& Co.

Talbot, P. A. (1926a). The Peoples of Southern Nigeria, Vol. 2, p. 378. Oxford: University Press for the Crown Agents.

Talbot, P. A. (1926b). The Peoples of Southern Nigeria, Vol. 2, p. 372. Oxford: University Press for Crown Agents.

Waller, H. (1950). Lancet, 258, 53.

Wickes, I. G. (1953a). Arch. Dis. Childh. 28, 15 I.

Wickes, I. G. (1953b). Arch. Dis. Childh. 28, 232.

Wickes, I. G. (1953c). Arch. Dis. Childh. 28, 332.

Wickes, I. G. (1953d). Arch. Dis. Childh. 28, 416.

Wickes, I. G. (1953e). Arch. Dis. Childh. 28, 495.

Widdowson, E. M. \& McCance, R. A. (1943). Lancet, 244, 230.

Williams, J. C. (1936). Food Res. $1,537$.

Woodruff, A. W. (I954). Brit. med. $\mathscr{f}$. (In the Press.)

\title{
The Interpretation of the Clinical Stigmata of Nutritional Deficiency
}

\author{
By R. Passmore, Department of Physiology, University of Edinburgh
}

At the first scientific meeting of The Nutrition Society held at the Physiological Laboratory, Cambridge, on 18 October I94I, the subject for discussion was the Evaluation of Nutritional Status (Proceedings of The Nutrition Society, 1944, 1, $7^{-18)}$. Both Woolf (1954) and myself deal here with parts of this problem. It is 
indeed no accident that this theme should be recurrent in our Proceedings. A full meeting was devoted to it in March 1948 (British Fournal of Nutrition 1948, 2, $147-175)$. Perhaps there is no aspect of nutrition, in which the work of the members of this Society is so important, for now nearly all governments have assumed that it is part of their responsibility to have an active nutrition policy working to provide a sufficiency of foods for all sections of the people, and all nutrition policies, if they are to be practical, must rest on a valid assessment of the nutritional status (or nutriture) of the community for whom the policy is intended.

At the first meeting of our Society the opening speaker was our present Chairman, Dr L. J. Harris, and he was followed by H. M. Sinclair and B. S. Platt. Sinclair's comprehensive review on The Assessment of Human Nutriture (Sinclair, 1948a) and the report of the Joint FAO/WHO Expert Committee on Nutrition, of which Professor Platt was a member, on the assessment of nutritional status (FAO/WHO: Joint Expert Committee on Nutrition, 195I) are the two most important accounts of this subject in the literature. I own that I hesitated to accept the Programme Secretary's invitation to speak at this meeting, when there are other members of our Society more experienced than I in this subject. Much of my contribution will only be underlining and emphasizing what has already been written. I regard the $\mathrm{FAO} / \mathrm{WHO}$ report as a thoroughly practical document. It was drawn up by persons who normally work in Chile, Egypt, France, Holland, India, Italy, Malaya, South Africa, West Africa and the United States and so represent a remarkable uniformity of informed opinion. My experience in assessing nutrition, which has been gained in many countries of the world, is in almost complete agreement with this report, and my chief excuse for presenting this paper is to bring the report to the attention of those who may not already have seen it.

There are five distinct methods for assessing the nutritional status of a community, each of which may be made quantitative. These are:

(I) Dietary surveys

(2) A study of vital statistics

(3) Anthropometric measurements

(4) Biochemical and physiological studies

(5) Clinical surveys.

I am only concerned here with the last, but in practice it is always important to consider all five together. Nutrition is a complex subject and the interpretation of data collected in the field is never straightforward. Whenever possible it is essential to cross-check by reference to other and independent data.

In clinical work nutritional disorders can be conveniently described in two groups (Table I). In group A, I put ten major conditions; each has a well-defined symptomatology and is associated with definite clinical and pathological changes. The recognition of these disorders is as straightforward (or as difficult) as any problem in clinical diagnosis can be. There are also certain other well-defined diseases, notably trachoma and tropical ulcer, which, although not primarily nutritional disorders, are to be found only amongst inadequately nourished persons. 
Table I. Nutritional disorders

Group A, well-defined nutritional diseases
I. Chronic starvation
2. Obesity
6. Pellagra
3. Kwashiorkor
Nutritional anaemia
7. Scurvy
8. Rickets
9. Osteomalacia
5. Beriberi
I0. Keratomalacia

Group B, conditions frequently associated with a defective diet

I. Conditions of the skin
(a) Hyperkeratosis
(b) Crazy-pavement dermatosis
(c) Nasolabial dyssebacia
(d) Hyperkeratosis follicularia
(e) Genital eczema

2. Conditions of the lips

(a) Angular stomatitis

(b) Cheilosis
3. Conditions of the eye

(a) Night-blindness

(b) Xerophthalmia and Bitot's spots

(c) Superficial keratitis

(d) Conjunctivitis and photophobia 4. Conditions of the tongue

(a) Glossitis

5. Dental conditions

(a) Dental caries

(b) Malocclusion

(c) Gingivitis

6. Goitre

Group B contains a variety of conditions, symptoms and physical signs frequently found in association with deficient diets. There is as yet no agreement on either what constitutes these stigmata of nutritional disorders or on the aetiological factors responsible for the appearance of most of them. Members of the Society will recall that other lists have been presented to us, notably the one used by the Oxford Nutrition Survey (Sinclair, I948b) and Nicol's (1952) classification, which proved so useful in his admirable Nigerian surveys. The FAO/WHO report also contains a long list. Group B (Table I) I would regard as a minimum with which to begin recording in a clinical survey. Subdivisions and extensions will almost certainly be required, varying according to locality and circumstance.

Here I must interpose the opinion that any clinical assessment of nutrition in the absence of evidence of the diseases in group $A$ and the signs and symptoms in group B is a waste of time, and misleading. Muscle tone and posture are not readily susceptible to measurement or closely related to dietary intake: clinical assessments based on impressions of their character are worthless. Jones (1938) showed in a well-planned experiment that even experienced school medical officers were unable to grade British schoolchildren consistently by inspection. Yet others continue to attempt this impossibility. Such clinical impressions may be useful in assessing an individual child for treatment, but should play no part in group assessments.

A real difficulty arises in the recording of minimal signs in group B. I always have with me a good hand lens, but no further optical aid. The use of such aids may well tempt the inexperienced to record disease where none is present. Sinclair (I948a) has told us that seven U.S.A. and Canadian nutritionists after a slit-lamp examination of his cornea expressed the opinion that he had an ariboflavinosis. In fact he had been taking an excess of this vitamin for 2 years. However, the recording of minimal signs is difficult. A conjunctiva may not be quite clear, a skin 
a little rough and dry or a muco-cutaneous junction a little uneven. Should such be recorded? I confess in these not uncommon cases I have always fallen back on my experience as a teacher in a medical school. Would I dare demonstrate this case to undergraduates (a critical body) as an example of xerophthalmia, hyperkeratosis or angular stomatitis? If the answer is no, then I don't record its presence.

Another important point is always to look for signs of deficiency diseases where they are most likely to be found. Children of 5 years of age and upwards can usually be conveniently examined when collected together at school. They have seldom been overlooked. Children under 5 years are less easily assembled and so more difficult to examine effectively. The great liability of toddlers to deficiency diseases has in consequence been frequently overlooked, especially in the tropics. Indeed it is only in the last ro years that it has become generally realized that during the period just after weaning the child is most 'vulnerable' nutritionally. This knowledge has lead to an increased interest in the customs and practices of weaning in many parts of the world, notably in Africa. Here clinical assessments have led to anthropological studies (Clark, 1953). In western European countries with well-developed maternity and child-health surveys, there is so little of nutritional disorders in the young that systematic clinical surveys are probably a waste of time. In Great Britain nutritional disorders are probably most frequently found in old persons, especially those who lead a solitary life. Any clinical nutritional survey in this country must be carefully checked to ensure that these old people have not been passed by, as can so easily happen. Indeed the very causes of a disorder such as bachelor scurvy may be that the social services have passed by the old man, unaware of his existence. In times of general food shortage and possible famine, it is important not to be misled by the condition of the people found in the street. For persons weak with hunger may be unable to go abroad. Proper sampling is an essential for any survey.

The unequivocable presence of any of the stigmata listed in Table I should at once draw the attention to the diet, but it must not be too readily assumed that a dietary factor is the cause. All of these conditions may arise from non-dietary causes and despite an apparently satisfactory food intake. Whenever possible a therapeutic trial should be made. If the signs disappear after a nutritional remedy or a dietary improvement, their dietary origin may be reasonably assumed. Such trials may not be possible, and then perforce reliance must depend on a dietary history. Time spent on seeking such information is never wasted.

In interpreting clinical signs and failure to grow, it is important to assess the extent of coincidental infections. The presence of chronic malaria, heavy worm infestations or congenital syphilis may seriously interfere with nutrition and increase the requirements for nutrients. To assess nutriture clinically in the tropics, one must be an amateur malariologist, something of a venereologist, and have more than a casual acquaintance with the behaviour of parasitic worms. Here I make my one point of dissent from the FAO/WHO Committee. I can see no place for the use of non-medical personnel in clinical surveys. Short cuts may always lead to danger. So many factors may determine nutriture that those who attempt to 
assess it clinically must have a broad general training both in pathology and diagnosis. Exposure and trauma may produce conditions that mimic closely nutritional disorders. Children who run barefoot often have dry, rough, atrophic skin below the knee, associated with ulcers and skin cracks. Whereas these signs are usually associated with nutritional defects when distributed generally over the body, they may be discounted somewhat below the knee. Indeed children, who are otherwise healthy and feed well, are not infrequently seen with these conditions well marked on the legs and feet. In adults prolonged exposure of the conjunctiva to dust and glare, old trauma and past infections may well mimic early xerophthalmia.

Some of the signs of deficiency can undoubtedly be caused by a lack of one or other of several nutrients. Thus angular stomatitis may arise from ariboflavinosis, iron deficiency or, in animals at least, pyridoxin deficiency (Ramalingaswami \& Sinclair, 1950). The erratic and, in my experience, quite unpredictable response of persons with severe skin hyperkeratosis and especially follicular hyperkeratosis to fish-liver oil preparations suggests a multiple aetiology for these conditions. Further, I have never been able to separate the common cases of nutritional glossitis into those attributable to lack of riboflavin and those attributable to lack of nicotinic acid with the confidence and certainty that some text-books suggest. I have seen not a few malnourished persons with glossitis whose tongues have not responded to either of these vitamins, but have improved slowly with a good diet. This variability both in aetiology and therapeutic response may worry the clinician, but will not surprise the biochemist. There appears now to be no doubt that many different metabolic pathways converge onto a common metabolic pool, from which both the material and the energy necessary for organic syntheses are made available. The integrity of histological structure is presumably dependent on such syntheses, and it is not difficult to see how a variety of chemical disturbances, affecting the incoming channels may upset in a similar manner a central controlling mechanism. Thus different biochemical lesions may lead to the same structural abnormality.

That an excess of one nutrient may upset such a balance and increase the requirements for another has been elegantly shown by Richards (1949). In the rat, an excess of thiamine may promote or condition a pantothenic-acid deficiency on a diet which contains a sufficiency of pantothenic acid for normal thiamine intake. A similar excess of other factors might be expected to increase requirements for different vitamins, and such disproportions in intake of nutrients might well provide the explanation of some clinical difficulties: I have been on the look out for, but cannot yet record, a convincing clinical example.

I think that clinicians would be wise to be more alive to the possibilities of antivitamins in natural foods. Hitherto the chemical laboratories have produced far more antivitamins than have been identified in nature. The brilliant discovery by Green in $193^{6}$ (Green, Carlson \& Evans, 1942) of an antithiamine in the flesh and viscera of carp fed to silver foxes explained the outbreak of a disease akin to Wernicke's encephalopathy in these animals. Additional thiamine both prevented and cured the disease. Dicoumarols were discovered as a result of the careful investigations by veterinarians of haemorrhagic disease in cattle. Human medicine has no 
comparable achievements in the field. Manson-Bahr (I95I) has suggested that the epidemiology of some types of nutritional macrocytic anaemia in the tropics can best be explained by postulating a seasonal variation of folic-acid antagonists in the foods. There is good evidence for the presence in maize of growth-preventing factors that may be toxic and may include a nicotinic-acid antagonist (Borrow, Fowden, Stedman, Waterlow \& Webb, I948; Kodicek, I949). The brothers Gillman (Gillman \& Gillman, 195I) have attacked with delightful ferocity the practical value of the tables of food analysis that we all must use. 'There is,' they write, 'a vast difference between the chemical analysis of a food and its biological usefulness'. I think that they have greatly overstated their case. Nevertheless they have produced much evidence that clinical states often cannot be correlated accurately with ascertained intakes of nutrients, as calculated by current methods of chemical analysis. I press these points, for it seems that many of the common stigmata of nutritional diseases cannot be adequately accounted for by simple deficiencies. I shall be surprised if we have much more to learn of the effects of lack of single nutrients in man. I think we have only just begun to appreciate the importance in human nutrition of antivitamins and the imbalance of nutrients. Advances can come only from a close correlation of clinical findings, dietary studies and chemical analyses.

\section{SUMMARY}

Clinical examinations can contribute greatly to the assessment of nutritional status, if they allow the accurate recording of the incidence of well-defined physical signs and symptoms in a properly selected sample of a population. The incidence of the signs must always be interpreted in relation to a full dietary history and, if possible, correlated with a dietary survey. Only therapeutic trials can establish a nutritional diagnosis with certainty. The absence of definite physical signs of nutritional diseases does not signify that the nutrition of a group is satisfactory. Other methods of assessment, notably dietary surveys, the study of vital statistics and anthropometric data, are probably more sensitive indices of minor departures from adequate levels of food intake. In the absence of definite physical signs, clinical impressions of nutritional status are subjective and frequently misleading: no direct objective checks between different observers are possible. Nevertheless in many poor districts in the tropics and in times of famine and disaster, clinical methods provide the most rapid and reliable of assessments. The FAO/WHO Committee's report (FAO/WHO: Joint Expert Committee on Nutrition, 195I) provides an admirable background of our present knowledge of methods of assessment of nutritional status.

\section{REFERENCES}

Borrow, A., Fowden, L., Stedman, M. M., Waterlow, J. C. \& Webb, R. A. (1948). Lancet, $254,752$. Clark, F. Le G. (1953). Nutrition, 7, 82.

FAO/WHO: Joint Expert Committee on Nutrition (1951). Tech. Rep. Wld Hlth Org. no. 44.

Gillman, J. \& Gillman, T. (195I). Perspectives in Human Malnutrition. New York: Grune \& Stratton. Green, R. G., Carlson, W. E. \& Evans, C. A. (1942). F. Nutr. 23, 165. 
Jones, R. H. (1938). F. R. statist. Soc. ror, I.

Kodicek, E. (1949). Brit. F. Nutr. 2, 373.

Manson-Bahr, P. E. C. (195I). F. trop. Med. (Hyg.) 54, 89.

Nicol, B. M. (1952). Brit. F. Nutr. 6, 34.

Ramalingaswami, V. \& Sinclair, H. M. (1950). Brit. $\mathscr{f}$. Nutr. 4, xii.

Richards, M. B. (1949). Brit. F. Nutr. 3, 109.

Sinclair, H. M. (1948a). Vitam. \& Horm. 6, 1or.

Sinclair, H. M. (1948b). Brit. F. Nutr. 2, r6r.

Woolf, B. (1954). Proc. Nutr. Soc. 13, 82. 